\title{
Awareness of Tourette Syndrome in Malaysia
}

\author{
Gunasegaran Karuppannan, Angela Chan Nguk Fong, Fazal Mohamed Mohamed Sultan, \\ and Datu Masjidin Moksan
}

\begin{abstract}
In Malaysia not many parents, including teachers, are aware and have any knowledge about Tourette Syndrome. Tourette Syndrome is a disorder due to neurological factors characterized by repeated, stereotyped, unintentional movements and vocalizations called tics. In Malaysia, a few Tourette Syndrome students have been identified as not going to school because they are bullied due to their motor and vocal tics. So, in Malaysia we still don't have any special teaching and learning modules as an inclusive program for the Tourette Syndrome students. The awareness and understanding about Tourette Syndrome among Malaysian citizens are also lacking, therefore a module to create awareness among parents, teachers and public should be developed. Until today, nothing has been looked into the matter of Tourette Syndrome by any of the Malaysian government departments. This makes the students with Tourette Syndrome not getting proper education and some are not even going to school. So, with the help of Ministry of Women, Family and Community Development and Ministry of Education the total number of students in Malaysia with Tourette Syndrome must be identified.
\end{abstract}

Key words - bullied, inclusive program, module, neurological disorder, proper education, Tics.

\section{INTRODUCTION}

Malaysia has shown a positive development in providing education for children and adolescents with disabilities since Independence. However, there are still challenges, for example unsupervised and unstructured early intervention programme, poor infrastructural and technological accessibility, financial constraint, low level of readiness among special and general educators, and individual selfconflict. Only by acknowledging and seriously addressing these challenges will then lead us to think about the practical solutions for these obstacles. At the same time, there is a need for a multi-stakeholder participatory collaboration to efficiently plan, implement, monitor and evaluate steps taken to achieve inclusivity for persons with disabilities in local education sector. Through active multi-stakeholder participation and collaboration, different obstacles faced by different parties can be properly addressed, thus effective coordination between all parties involved can be achieved [1]. On the other note, all recommendations made by

Published on July 27, 2021.

Gunasegaran Karuppannan, Centre for Graduate Studies, Universiti Selangor (UNISEL), Malaysia.

(Corresponding e-mail: drguna ${ }^{\circledR}$ unisel.edu.my)

Angela Chan Nguk Fong, Industrial Training Coordinator, Faculty of Education and Social Sciences, Universiti Selangor (UNISEL), Malaysia. (e-mail: angelac@ ${ }^{@}$ unisel.edu.my)

Fazal Mohamed Mohamed Sultan, Center for Research in Language and Linguistics, Universiti Kebangsaan Malaysia (UKM), Malaysia. (e-mail: fazal@ukm.edu.my)

Datu Masjidin Moksan, Open University Malaysia (OUM), Malaysia. (e-mail: kibaguku@oum.edu.my) research participants in this research should be taken up by Ministry of Education and other related bodies for implementation. As emphasised by [2], Malaysia lacks in terms of large-scale psychopathological research to effectively identify the exact number and geographical position of persons with special learning needs. One of these is Tourette Syndrome, where the awareness and understanding about Tourette Syndrome among Malaysians are very far behind.

The mission of education in Malaysia is to develop a world-class education system which will realize the full potentials of all Malaysians and fulfill the national aspiration of attaining a developed country status by 2020 . This Malaysian mission of education endorses the UNESCO declaration of 'Education for All' and the 'No Child Left Behind' policy for the purpose of sustainable development [3]. The transformation of these policies is to practice presents challenges to Malaysian educators, specifically the educators in the area of special education in Malaysia [4].

This paper will explore special education in the context of children with Tourette Syndrome to obtain insights into the challenges faced by educators of special education in Selangor. These insights form the feedback to facilitate the improvement of special education for children with Tourette Syndrome in Selangor. Studies have shown that teachers welcome positive changes to special education and also would welcome suggested teaching and assessment method for Tourette Syndrome students. The National Education Blueprint (2013-2025) by the Ministry of Education clearly states the evolutionary process for special education [5]. The government has set a target for $75 \%$ of students with special needs to be enrolled in inclusive programmes by 2025 [6]. Therefore, this research is to improve the education system for the Tourette Syndrome students to be enrolled in inclusive program which is relevant to the Malaysian Government Policy.

\section{PROBlem STATEMENT}

Lately many Malaysians are found to be affected with Tourette Syndrome but not many parents including teachers are aware and have any knowledge about Tourette Syndrome. Tourette Syndrome is a neurological disorder characterized by repetitive, stereotyped, involuntary movements and vocalizations called tics [7]. The early symptoms of Tourette Syndrome are typically noticed first in childhood, with the average onset between the ages of 3 and 9 years.

This Syndrome occurs in people from all ethnic groups; males are affected about three to four times more often than females [8]. Although students with Tourette Syndrome often function well in the regular classroom, but frequent 
tics can greatly interfere with academic performance or social adjustment [9]. All students with Tourette Syndrome need a tolerant and compassionate education setting that both encourages them to work to their full potential and is flexible enough to accommodate their special needs.

In Malaysia a few Tourette Syndrome students had been identified as not going to school because they are bullied due to their motor and vocal tics. So, in Malaysia we still don't have any special teaching and learning module as an inclusive program for the Tourette Syndrome students. The awareness and understanding about Tourette Syndrome among Malaysian citizens are also lacking, therefore a module to create awareness among parents, teachers and public should be developed. Until today, nothing has been looked into the matter of Tourette Syndrome by any of the Malaysian government departments. This makes the students with Tourette Syndrome are not getting proper education and some are not even going to school. So, with the help of Ministry of Women, Family and Community Development and the Ministry of Education, the total number of students in Malaysia with Tourette Syndrome must be identified.

\section{LITERATURE REVIEWS}

Tourette Syndrome is a disorder due to neurological factors and it is identified by motor and vocal tics [10]. 'Tics' are simple twitches or grunts or sometimes there are more complex tics, for example series of repetitive movements, shouting or repeating phrases, or words. 'Coprolalia' is a common complex verbal tic which means involuntarily shouting out swear words. While 'echolalia' is another complex verbal tics which means repeating others' words [11], [12]. Dr. Georges Gilles de la Tourette is the pioneer neurologist who first identified these tics as a syndrome which he named as Tourette Syndrome.

Tourette Syndrome's early symptoms could be seen during childhood, with the average ages between 3 to 9 years. Tourette Syndrome occurs in man about three to four times more often than in ladies and it also occurs in all ethnic groups. Studies show that around 200,000 Americans are affected with this severe form of Tourette Syndrome. This figure also estimates that as many as one in 100 has Tourette Syndrome with chronic motor or vocal tics. The symptoms of Tourette Syndrome can last for a whole lifetime, but mostly the symptoms will be the worst in their early teens, and it might reduce in their late teens and continue until adulthood [13].

The symptoms of Tourette Syndrome are always classified as either simple or complex. The example of simple motor tics, which are sudden, brief, repetitive movements that involve a limited number of muscle groups, are eye blinking, facial grimacing, eye movements, shoulder shrugging, and head or shoulder jerking. Simple tics involving vocal are repetitive throat-clearing, grunting sounds or sniffing [14]. Apart from these complex tics are also distinct and coordinated patterns of more serious movements involving certain muscle groups. Some of the serious movement could be facial grimacing combined with a head twist and a shoulder shrug. Other complex motor tics may actually appear purposeful, including sniffing or touching objects, jumping, hopping, twisting or bending. Other types of simple vocal tics are throat-clearing, sniffing, barking, grunting, or snorting. Some complex vocal tics involves words or phrases. Nevertheless, the most disabling tics include motor movements that result in self-harm such as punching oneself in the face or vocal tics including coprolalia (uttering socially inappropriate words such as swearing) or echolalia (repeating the words or phrases of others). However, coprolalia can only be seen in a small group maybe ten to fifteen percent of Tourette Syndrome individuals. Some tics are preceded by an urge or sensation in the affected muscle group, commonly called a premonitory urge. Some with Tourette Syndrome will describe a need to complete a tic in a certain way or a certain number of times in order to relieve the urge or decrease the sensation [15]. Although students with Tourette Syndrome often function well in the regular classroom, but tics can greatly interfere with academic performance or social adjustment. After a comprehensive assessment, students should be placed in an educational setting that meets their individual needs. Students may require tutoring, smaller or special classes, and in some cases special schools [16].

In fact, people with Tourette Syndrome have the same intelligence and lifespan as ordinary people. The only difference is that they have motion and vocal tics which could be interrupting and annoying. In general, there are at least two motion tics and one vocal tic within a people with Tourette Syndrome. Tics will increase when the children are feeling excited to go for a vacation or stressed out before taking an examination. In contrast, tics will be lessened when they are engaging in more relaxing activities. Some children can control the chances of tic occurrence, but they cannot really prevent it from happening.

People with Tourette Syndrome could also lead healthy and active lives as ordinary people. However, they are also often faced with behavioral and social challenges which are associated to the tic disorder. The most common problems are difficulty to concentrate in learning, hyperactivity, learning ability and disciplinary issues, anxiety, and depression. Typically, children with Tourette Syndrome often show Attention Deficit Hyperactivity Disorder (ADHD) at the beginning. They have poor self-control and hardly to pay attention. Most of the time, Tourette Syndrome kids have difficulties in reading, writing, calculating, and concept understanding. However, these are not related to the children's intelligence. Besides, they are faced with behavioral and emotional control problems. They tend to act aggressively, provocatively, irritably and show behaviors that cannot be accepted by the society. People with Tourette Syndrome may have excessive worry, fear, or shyness. Sometimes it could be a periodic depression from time to time. Obsessive compulsive disorder (OCD) is another challenge encountered by them as well [17]. They might have repetitive, harmful actions or intrusive thoughts, for instance, checking whether the door is locked or washing hands repeatedly. In spite of that, Tourette Syndrome children may face social interaction issue in schools. They are always alone and do not mingle around well with peers. Last but not least, they might have sleeping disorder problem such as difficulty to fall asleep, short sleep, 
bedwetting, sleepwalk or fudge.

Tourette Syndrome students must have a more receptive and benevolent setting which will inspire them to work to their full potential. This must also be malleable enough to be useful for their special needs. For example, the setting might be an individual place to study, flexible time and place for exams, or if the symptoms disturb the students' capability to write then we should think of an oral exam. For Tourette Syndrome students a flexible timing for exam will cut down their stress.[18].

\section{SPECial EdUCATION IN Malaysia}

In Malaysia, the special education program is divided into three types, which are special schools, integration program and the inclusive program. The special schools are built for the blind and deaf students. The integration and inclusive programs are conducted in the normal schools [19]. The students who are categorized under special education are all categories of autism, ADHD, Down Syndrome, Dyslexia, and slow learners. Tourette Syndrome is still considered a new term in Malaysia. Therefore, the understanding and awareness of Tourette Syndrome among Malaysian is very important to help those who suffer from tic disorder. With the awareness, children may get diagnosed earlier instead of being punished by parents due to their uncontrollable tics. Besides, they can also receive behavioral therapies or medications if the tics cause pain or injury; interfere with school, or daily life; or cause stress. At the same time, Tourette Syndrome kids will not get unnecessarily punished by their teachers or teased by peers in schools if most of the people in society understand their conditions.

Children with Tourette Syndrome have the same intelligence as normal kids as mentioned earlier, but many of them may need special education. This is due to tic disorder, ADHD, learning difficulties, anxiety and emotion disorder within the children may affect their learning. Tics and challenges faced by Tourette Syndrome kids can be alleviated via special measures in a special education classroom. This allows them to learn better and more effectively. This is an important issue to be addressed because any students who are identified as "health impairment" have the right to accept equal education as other students. Special education can minimize the impact of Tourette Syndrome students' learning difficulties and to realize their learning potential.

Everyone's brain structure is different and Tourette Syndrome kids are just a little bit more special than others. They have the same right to live happily like other children. They are doing their best to accept their own differences despite various challenges they faced and seek understanding from the society. Therefore, as a society with care and mindfulness, Malaysians need to understand and be aware of the needs of Tourette Syndrome kids.

\section{CONCLUSION}

Therefore, in Malaysia, proper research and steps should be taken by the Ministry of Education in order to help the Tourette Syndrome students to get proper education. The Department of Special Education under the Ministry of Education should study to put the Tourette Syndrome students under the category of special education.

\section{ACKNOWLEDGEMENTS}

We would like to thank the Selangor Government of Malaysia for funding this research under the SEMESTA-MBI Grant and this work was supported by Universiti Selangor (UNISEL).

\section{REFERENCES}

[1] Muhamad Nadhir Abdul Nasir and Alfa Nur Aini Erman Efendi, "Special education for children with disabilities in Malaysia," Geografia, Malaysian Journal of Society and Space, vol. 12, no. 10 pp. 78-87, August 2016.

[2] Lay Wah Lee and Hui Min Low, "The evolution of special education in Malaysia," British Journal of Special Education, Vol. 41, No. 1, pp. 42-58, March 2014.

[3] Rutil Taising and Gunasegaran Karuppannan, "Principals' Management Empowerment Practices and Its Relationship with Work Satisfaction Among School Mid-Level Administrators", Selangor Humaniora Review, Vol. 4, No. 2, pp. 1-14, December 2020

[4] Sufean Hussin, Quek Ai Hwa, \& Loh Sau Cheong, Policy into Practice: The Challenge for Special Education in Malaysia, Kuala Lumpur: University of Malaya, 2012

[5] Malaysia Education Blueprint 2013-2025, Annual Report 2017 Cyberjaya: Ministry of Education Malaysia, 2018.

[6] Lay Wah Lee \& Hui Min Low, "The evolution of special education in Malaysia," British Journal of Special Education, Vol. 41, No. 1, pp. 42-58, March 2014.

[7] J. Piacentini D. W. Woods, L. Scahill, S. Wilhelm, A. L. Peterson, S Chang, G. S Ginsburg, T. Deckersbach, J. Dziura, S. Levi-Pearl, J. T. Walkup, "Behavior therapy for children with Tourette disorder: a randomized controlled trial", JAMA, Vol. 303, No. 19, pp. 19291937, November 2010

[8] G. A. L. Evans, A. Wittkowski, H. Butler, T. Hedderly, P. Bunton, "Parenthing Intervention for Children with Tic Disorders: Professionals' Perspectives," Journal of Child and family Studies, 25 , pp. 1594-1604. November 2015.

[9] Malaysia Education Blueprint 2013-2025, Annual Report 2017, Cyberjaya: Ministry of Education Malaysia, 2018.

[10] H. M. Feldman and M. I. Reiff, "Attention Deficit -Hyperactivity Disorder in Children and Adolescents," The New England Journal of Medicine, Vol. 370, No. 9, pp. 838-846, Feb 2014.

[11] K. St P. McNaught and J.W. Mink, "Advances in Understanding and Treatment of Tourette Syndrome," Nature Reviews Neurology, Vol 8, No. 7, pp. 667-676, November 2011.

[12] T. Roger, C. Alan and C. Elizabeth, "Perceived Usefulness of Learning Strategies by Children with Tourette Syndrome Plus, Their Parents and Their Teachers," Vol 72, No. 3, pp. 263-275 Health Education Journal, April 2021

[13] A. Chaturvedi, B. C. Gartin and N. L. Murdick, "Tourette Syndrome Classroom Implications," Physical Disabilities: Education and Related Services, Vol. 30, No. 1, pp. 53-66, Spring 2011.

[14] G. Karuppannan, (December, 2020). Kesedaran Terhadap Tourette Sindrom. Early Intervention Program. [Online], Available: https//eipepic.my/blog-post/.

[15] K. Roger, "Tourette's Syndrome." The New England. Journal of Medicine, Vol. 363, No. 24, pp. 2332-2338, December 2012.

[16] A. Claussen, R, Bitsko, J. Holbrook, J. Bloomfield and K. Giordano, "Impact of Tourette Syndrom on School Measures in a Nationally Representative Sample," Journal of Development \& Behavioral Pediatrics, Vol.39, No. 1, pp 335-342, October 2018.

[17] W. Ruth, G. Cris, P. Emma, and M. J. Georgina, "Supporting students with Tourette Syndrome in secondary school: a survey of staff views." Journal of Research in Special Educational Needs, 16(4), pp. 1-17, October 2014

[18] S. Hussin, A. H. Quek and S. C. Loh, "Policy into Practice: The Challenge of Special Education in Malaysia," presented at the 11th International Conference on Experiential Learning, Sydney, Australia, December 8-12, 2008.

[19] Muhamad Nadhir Abdul Nasir and Alfa Nur Aini Erman Efendi, "Special education for children with disabilities in Malaysia," Geografia, Malaysian Journal of Society and Space, vol. 12, no. 10 pp. 78-87, August 2016. 


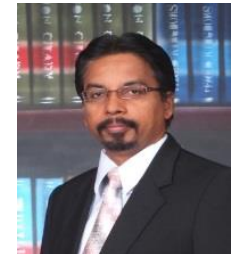

Gunasegaran Karuppannan was born in Kuala Selangor, Malaysia on $14^{\text {th }}$ November 1962 . He is an Associate Professor at Universiti Selangor (UNISEL) situated in Malaysia. Currently he holds the post as Deputy Dean in Centre for Graduate Studies office. He received his Bachelor Degree (Hons in Genetics) from Universiti Kebangsaan Malaysia (UKM), then he continued his study at University Malaya to get his Masters degree in Educational Management. Finally, he received his PhD from Universiti Putra Malaysia (UPM) in 2004 on Educational Administration focusing on Special Education. His major research interests are the area of Special Education. He is an active researcher who has participated in various international conferences as conference chairperson, keynote speaker or normal presenter and has published articles in a number of journals.

Associate Professor Dr Gunasegaran Karuppannan is also the Associate Secretary for Malaysia in the Asia Pacific School Psychology Association. Also, he is a member in Malaysian School Psychology Association and in Malaysian Psychology Association. Through-out his career, he had involved either as leader or member in a few research projects mainly focussing on special education. He has also written two books on special education.

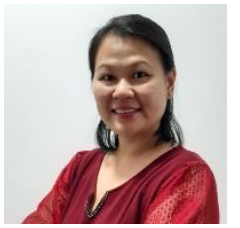

Angela Chan was born in Sarawak on 14th May 1984. She earned her B.Sc. in Cognitive Sciences from Universiti Malaysia Sarawak (UNIMAS) in the year 2006 and M.A. in Industrial and Organizational Psychology from Universiti Kebangsaan Malaysia (UKM) in 2010.

She is a Psychology Lecturer in the Department of Social Sciences at Universiti Selangor (UNISEL) for 11 years. She had been the Head of Programme for Bachelor of Industrial Psychology and also the Head of Department of Social Sciences. Currently, she is the Coordinator of Industrial Training for the faculty. Her research interest focuses on psychological well-being, personality and building up resilience among adolescent in various family and cultural context.

Mdm Chan currently is a member of Persatuan Psikologi Malaysia (PSIMA). She is also one of the manuscript reviewer for Selangor Humaniora Review (SHARE) for the year 2021.

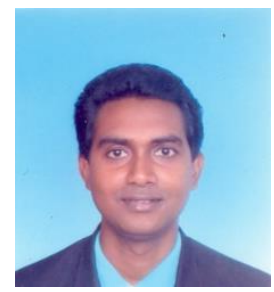

Fazal Mohamed Mohamed Sultan was born in Alor Setar, Kedah, Malaysia on $26^{\text {th }}$ March 1968. $\mathrm{He}$ is an Associate Professor at Universiti Kebangsaan Malaysia (UKM), situated in Malaysia. First, he received his Bachelor Degree (Hons) from California State University, Fresno, USA, then he continued his study at the University of Delaware, Newark, USA, to get his Masters degree in Formal Linguistics. Finally, he received his $\mathrm{PhD}$ from Universiti Kebangsaan Malaysia (UKM) in 2006 on Linguistics, focussing on Malay Linguistics.

$\mathrm{He}$ is a linguistics lecturer in the Linguistics Program at the Research Center for Language and Linguistics at UKM for 14 years. He had been the Head of the Linguistics Program. Currently, he holds the post as Head of Applied Linguistics Research Cluster at the Research Center for Language and Linguistics, Faculty of Social Science and Humanities. His primary research interests are the area of syntax, GIS, Orang Asli education and language. He is an active researcher who has participated in various international conferences as conference chairperson, keynote speaker or regular presenter and has published articles in several journals.

Associate Professor Dr Fazal Mohamed Mohamed Sultan is a lifetime member of the Malaysian Linguistics Association. His PhD was honoured as the Distinguished $\mathrm{PhD}$ Thesis in 2006. With that recognition, he has embarked on various research projects as a leader or member in more than 15 research projects worth more than RM1 million (accumulated). His research and publications were recognized, and he was granted a Young Researcher's Award in 2009 by UKM. Later, one of his papers co-written with his colleagues in a conference in Rome was awarded Best Paper Award in 2013. In 2016, one of his papers on aboriginal languages won him a prestigious award in Malaysia. His paper was awarded as the best paper in Social Sciences and Humanities Category by Majlis Penerbitan Ilmiah Malaysia (MAPIM) (Malaysian Scholarly Publishing Council). In the same year, he was again awarded BITARA UKM 2016 for his works on the Malay Language by UKM.

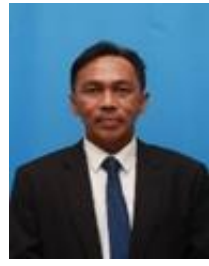

Datu Masjidin Bin Datu Moksan was born on 1st June 1970 at Kota Belud, Sabah. He was an alumnus from University Selangor; there, he completed his doctorship in education in 2019 and master of education (Discipline Management) in 2012. He obtained his Bachelor Degree in Science Social (History and Geography) in 2007 at University Malaysia Sabah. He also completed his diploma in Community Education Management 1999 at Institut Aminuddin Baki Genting Highland Pahang and diploma in Education 1991 at Maktab Perguruan Kinta, Ipoh Perak.

Dr. Datu is also a member of Asia Pacific School Psychology Association (APSPA) and his journal regarding Inclusive programs in Malaysia: Mainstream school teachers' acceptance towards special education students was publish in International Journal of Humanities an Education Research Volume2 Issue2 page 01-08. Apart from this he has presented various papers in national and International Conferences. 